\title{
Evaluation of Smoothing Effect of Wind Power Generator Aggregation on Power System Operation
}

\author{
T. Shimamura, D. Yamashita, K. Koyanagi, Y. Nakanishi and R. Yokoyama \\ Graduate School of Environment and Energy Engineering \\ Waseda University \\ Campus of Nishi Waseda - Shinjyuku-ku, Tokyo 169-8555, Japan \\ Phone/Fax number: +81 5286 3126, e-mail: t.shimamura@ fuji.waseda.jp
}

\begin{abstract}
This paper presents an approach to evaluate the smoothing effect of wind power generators on power system operation based on actual wind output data in Tohoku area in Japan. Conventional LFC (Load Frequency Control) model is used and the effect of the smoothing effect on frequency control is evaluated. For evaluating the smoothing effect, spectral analysis and integration of each frequency of wind outputs are utilized. In this study, the smoothing effect in multi areas is evaluated and the decrease of the power spectrum density of individual wind generator is confirmed by comparing with the density of integrated wind generators in wide areas. Moreover, we assume many wind generators are connected to power systems, and analyze the smoothing effect of integrating wind power generators on power system operation. By using this multigenerator model, the influence of generator integration on the LFC is evaluated by investigating the change of frequency deviations. In addition, a method to suppress the frequency deviation caused by wind power fluctuations is proposed with control of batteries equipped in Electric Vehicles (EVs)' in the power system model consists of wind generators and EVs.
\end{abstract}

\section{Key words}

Wind generators, Smoothing effect, Load Frequency Control (LFC), Electric Vehicle (EV)

\section{Introduction}

In recent years, renewable energy resources such as the photovoltaic and the wind power are socially remarked for the solution of the global warming and energy problems. Especially, the wind power generators are clean and sustainable energy. So they are planned to introduce 450 million $\mathrm{kW}$ by 2020,600 million $\mathrm{kW}$ by 2030 in Japan by the government. In general, the outputs of wind power generators are transmitted to the interconnected power system. However, the outputs of wind power generation are unreliable due to the change of wind conditions. Therefore, it is concerned that the increase of wind power generation in power grids may negatively affect the power quality such as frequency and voltage especially in power systems. Because of this, it is necessary to suppress the fluctuations of wind power generation.

When wind power generators are installed in wide areas as wind firms, the output of individual wind turbine fluctuates depending on the wind condition. Even though individual wind generator has a large power fluctuation, by integrating wind generators into a wind firm, the aggregated wind power fluctuation can be suppressed due to cancelling the output of individual wind generator, which is called the smoothing effect.

In this paper, we evaluate the smoothing effect of wind power fluctuations with actual operational data in Tohoku area (North part of Japan). We also examine the effect of wind power smoothing on the Load Frequency Control (LFC) in power systems.

If a large amount of wind power generators are connected to power systems, it is necessary to regulate or suppress the output fluctuations of wind generators to maintain the power quality. As a countermeasure, Battery Energy Storage System (BESS) is generally used. However, the capacity of BESS is required to be small because BESS is very expensive. Recently, Vehicle to Grid (V2G), which use batteries installed in Electric Vehicles (EVs) to supply electric power to power systems, is proposed. Then, the authors attempt to suppress the short term fluctuation of wind power outputs with controlling charged energy of batteries equipped in EVs. We carry out simulations using a two-area LFC model in case of introducing a large amount of wind power generators.

\section{Operational data of Wind Firms}

This paper uses actual operational data of wind power generation in Tohoku area. This area is the North part of Japan. Table 1 shows detail of wind power generators data (capacities and locations of various wind firms, and so on).

Table 1. Capacity and Location of various wind firms

\begin{tabular}{|c|c|c|c|c|}
\hline Site & Capacity(MW) & Place in Tohoku & Term & Time \\
\hline A & 135.25 & $\begin{array}{c}\text { The northern } \\
\text { part }\end{array}$ & & \\
\cline { 1 - 3 } B & 92.80 & The western part & $\begin{array}{c}2005 \sim \\
2006\end{array}$ & $\begin{array}{c}10 \\
\text { second }\end{array}$ \\
\cline { 1 - 3 } C & 63.90 & The eastern part & & \\
\hline
\end{tabular}




\section{The analysis method of the smoothing effect of Wind power fluctuation}

\subsection{Evaluation approach}

For the evaluation approach of the smoothing effect, the power spectrum density analysis is adopted in this investigation. The spectrum analysis shows a frequency period size of every output fluctuations. Integration of power spectrum density is calculated by equation (1) (refer to Fig. 1). This integration is equal to dispersion of fluctuation, and square root of this is a standard deviation.

$$
\sigma^{2}\left(F_{a} \sim F_{b}\right)=\int_{F_{b}}^{F_{a}} P(f) d t
$$

$\sigma^{2}(f)$ : desperation of frequency

$F_{a}, F_{b}$ : Period of frequency variation

$\mathrm{P}(f)$ : Power spectrum density

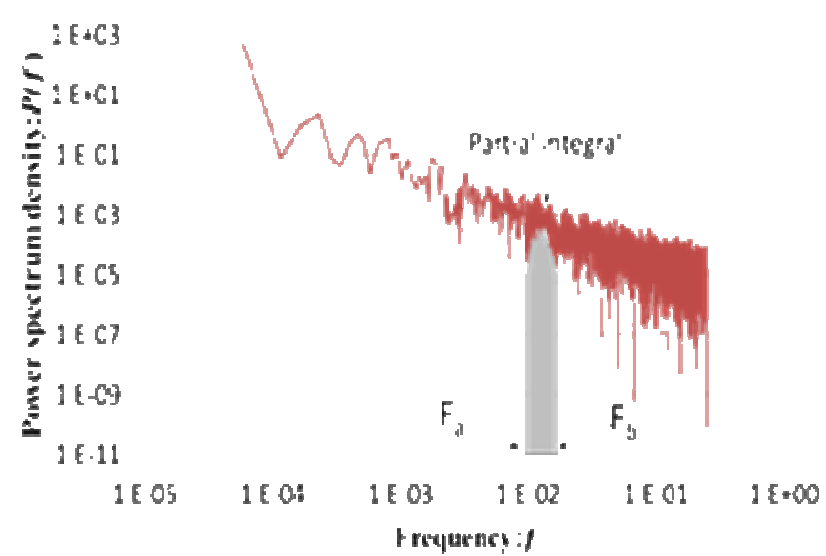

Fig. 1. Integration of each frequency

\subsection{Analysis results}

The analysis results of the power spectrum density and integration of each frequency in winter (October) is shown in Fig. 2 and Fig. 3 respectively. From Fig. 2, we can compare the multi wind generation sites' (ABC sites') power spectrum density with a single site's (A-1 site's) one. We confirm that the fluctuation of multi sites is about one tenth smaller than the single one.

In this study, power fluctuation within one hour concerning adjustment of supply and demand is focused on. From Fig. 3, the dispersions for periods of 20 30 and 30 40 minutes are larger than other periods in $\mathrm{ABC}$ site. Because there are correlations in periods of over 20 minutes, the smoothing effects in these periods cannot be expected. On the other hand, the smoothing effect for less than 20 minutes can be expected wind power fluctuation in this target area.

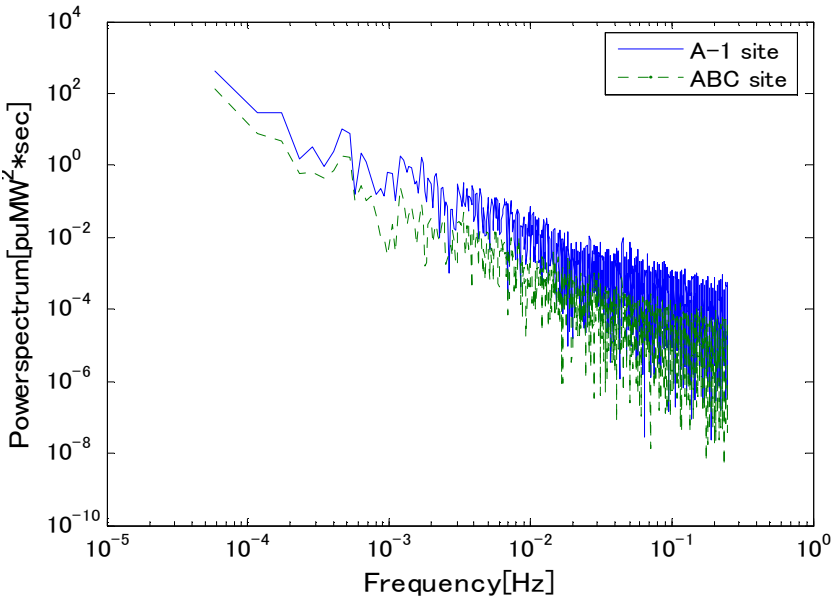

Fig. 2. Power spectrum density

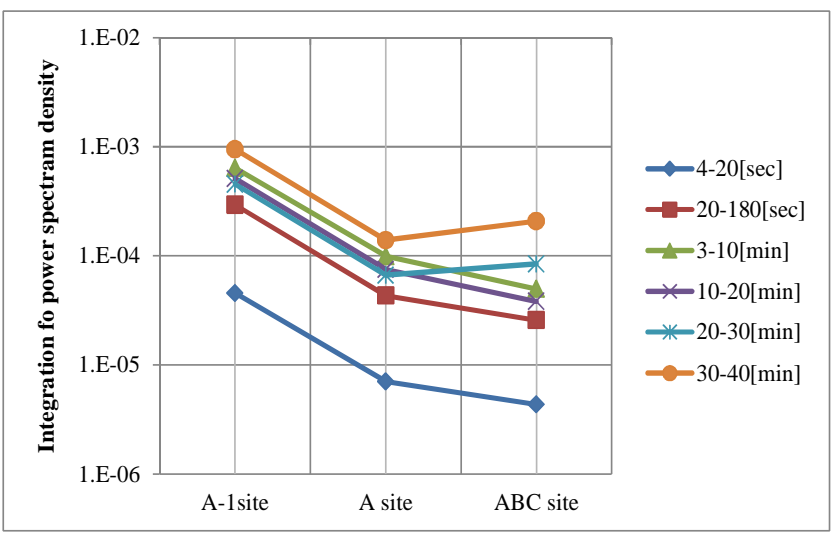

Fig. 3. Deviation each time period

\section{The influence on power system}

\subsection{Model of power system}

If wind power generators are distributed over wide areas, the output fluctuations of wind generations are suppressed because of the smoothing effect. In this chapter, we examine influences of the smoothing effect of wind power generation to the LFC. To evaluate the effects, simulations are carried out using an independent power system model installed of the wind power generation (2000MW). Fig. 4 shows the model of independent power system. The total capacity of power system is $4000 \mathrm{MW}$. Thermal power plants are consisted of re-heat cycle thermal power and hydro power plants are applied for the frequency adjustment. In this study, we defined the capacity of wind power generation $(2000 \mathrm{MW})$ as introduction amount $50 \%$ for the total power system capacity.

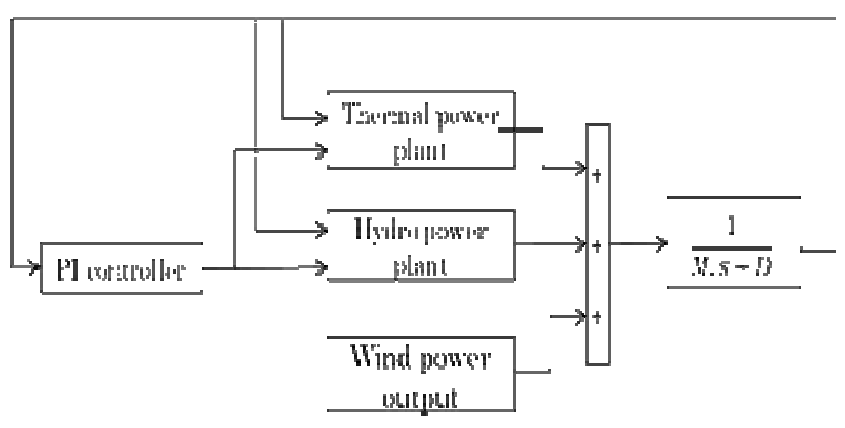

Fig. 4. Model of Power System 


\subsection{Output fluctuation of wind power}

The each operational date of A-1 site, A site and ABC sites (the capacities are 51.75, 135.25 and 291.25 MW respectively) is converted into $2000 \mathrm{MW}$ using the normalization method and applied to the simulation model. We calculate the following two cases. One is the intensive case (the wind power generators are only penetrated to A-1 site.), and the other is the wide spread case (the wind power generators are penetrated to A site or $\mathrm{ABC}$ sites).

\subsection{Simulation results}

Fig. 5 and 6 show the results of frequency deviation for A1 site and ABC sites. Fig. 7 shows the standard deviation of each case. If we compare the frequency deviations of A1 versus $A B C$ sites, the frequency deviation of $A-1$ site greatly exceeds $0.9 \mathrm{~Hz}$ and $-0.8 \mathrm{~Hz}$. By contrast, the deviation of $\mathrm{ABC}$ sites settle within $\pm 0.08 \mathrm{~Hz}$ because a whole wind power fluctuation is suppressed due to the smoothing effect. From Fig. 7, the standard deviation of $\mathrm{ABC}$ sites are about tenth part smaller than the A-1 site.

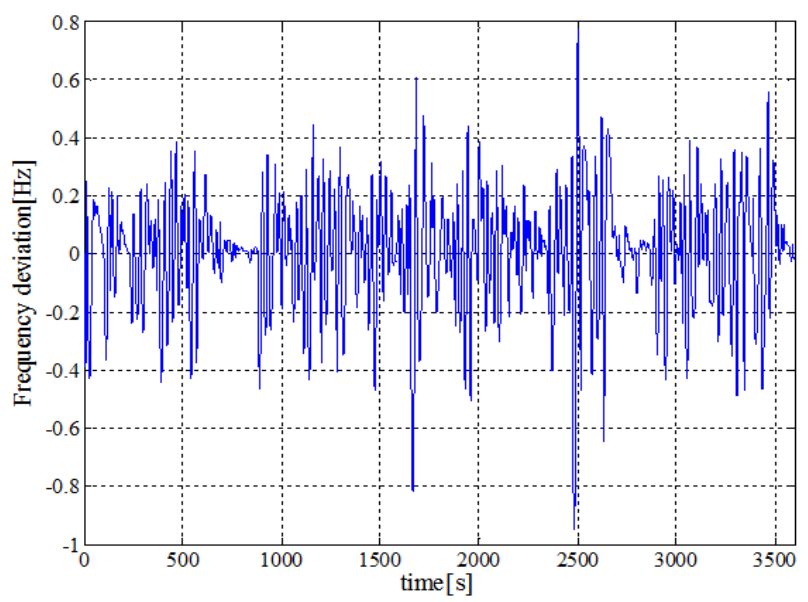

Fig. 5. Frequency deviation of A-1 site

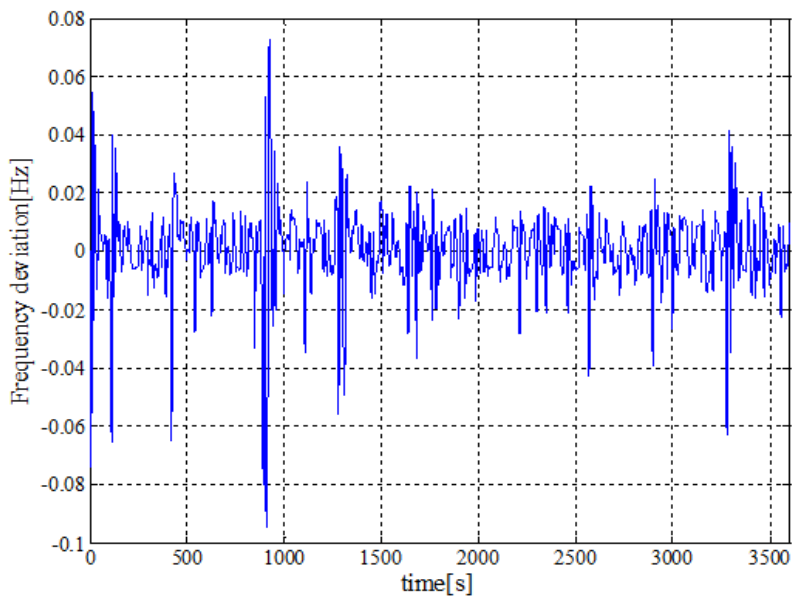

Fig. 6. Frequency deviation of $\mathrm{ABC}$ site

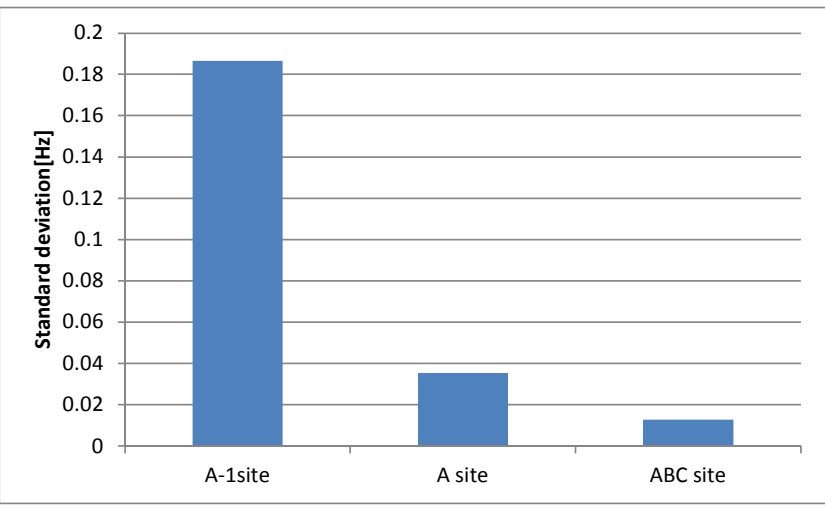

Fig. 7. Standard deviation of frequency

\section{Frequency regulation with a battery of EV}

\subsection{Two area interconnected power system}

The power companies are actually connected by the tieline. Therefore, we conduct frequency control simulation using a two-area interconnected power system shown in Fig.8. Table 2 shows the parameters for each area. For frequency control types in interconnected power system, Flat Frequency Control (FFC) and Tie line Bias Control (TBC) are adopted. This model consists of a generator model, thermal power plant model, hydro power plant model, load disturbance, wind power model and EV model. Thermal power plant consisting of re-heat cycle thermal power plant and hydro power plant are applied for the frequency adjustment. Thermal power plant changes the parameters of the governor, the reheater and the turbine, and distinguished different response characteristic of thermal plant. The outputs of thermal and hydro power plant are controlled by PI controller. Each area is connected by tie line, and wind power model and EV model is installed in area- 2.

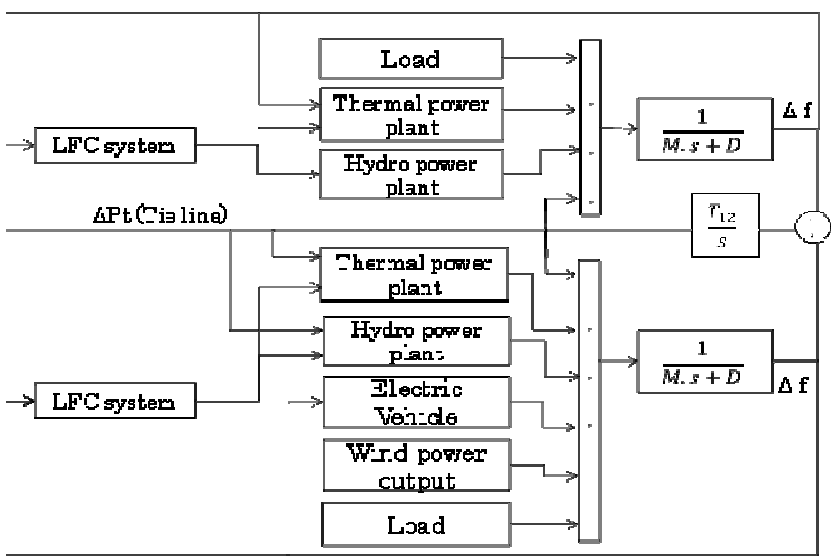

Fig. 8. Two-area interconnected power systems

Table 2. Parameter for Each Area

\begin{tabular}{|c|c|c|}
\hline parameter & Area-1 & Area-2 \\
\hline System capacity [MW] & 4000 & 2000 \\
\hline$f$ [Hz] & \multicolumn{2}{|c|}{50} \\
\hline LFC control type & FFC & TBC \\
\hline $\mathrm{M}_{\mathrm{i}}$ [p.u.MW $\left.\cdot \mathrm{s} / \mathrm{Hz}\right]$ & 0.32 & 0.24 \\
\hline $\mathrm{D}_{\mathrm{i}}$ [p.u.MW/Hz] & 0.01 & 0.005 \\
\hline $\mathrm{T}_{12}$ [p.u.MW/Hz$\cdot \mathrm{s}$ ] & \multicolumn{2}{|c|}{0.545} \\
\hline
\end{tabular}




\subsection{The model of EVs}

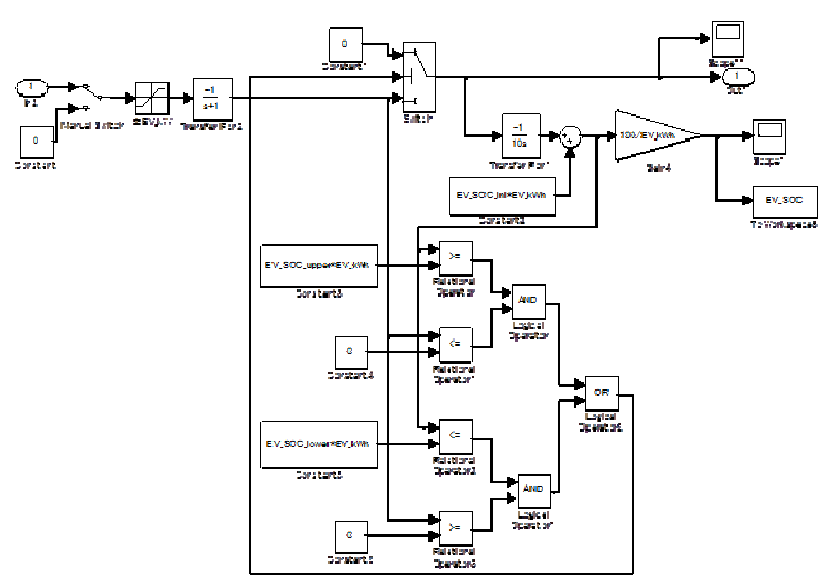

Fig. 9. EV model

EVs conduct their own batteries to charge until $85 \%$ of State-Of -Charge (SOC). Charging EVs make no response from power system signal. EVs which become $85 \%$ of SOC are defined controllable state and made to charge or discharge within the range of 80 to $90 \%$. Thus, controllable kWh capacity is decreased, but EV's driver can start driving with keeping over $80 \%$ of SOC. Moreover, discharging and charging hardly influence a battery life. The central load dispatching center sorts EVs according to received SOC information from EVs. If LFC signal requests to charge with signal, EVs start charging in ascending order of SOC. If LFC signal is discharge, EV is discharge in descending order of SOC. Thus, by setting up priority of discharge and charge, EVs of which the SOCs are further away from the average of EVs' SOC of are preferentially charged or discharged. As the result, the dispersion of total SOC becomes smaller. The SOCs of total EVs are synchronized. This let the central dispatching center regard EV batteries as one huge battery.

We assume that 2.5 thousand EVs are penetrated in an assumption area. Also, it is assumed that the SOC of each $\mathrm{EV}$ is synchronized, and EVs as a huge battery are introduced in frequency control. The discharge and charge power of EVs is limited by the number of EVs and SOCs. The power capacity of EVs is limited by the capacity of inverter and determined by the equation (2).

$$
E V_{k W}=N_{E V} \times C_{k W}[k W]
$$

Where,

$N_{E V}$ : the number of EVs

$C_{k W}$ : the capacity of inverter

EVs cannot charge or discharge over the power capacity and the energy capacity of battery. When the SOC of EVs reaches the upper limit, the controllable EVs cannot be charged. As well, when the SOC of EVs reaches the lower limit, the controllable EVs cannot be discharged. The upper limit and the lower limit of the SOC set up to $90 \%$ and $80 \%$ respectively, and the initial SOC is $85 \%$. The upper limit, lower limit and the initial SOC is calculated from $(3) \sim(6)$.

$$
E V_{k W h}=N_{E V} \times C_{k W h}[k W h]
$$

$$
\begin{aligned}
& S O C_{\text {Upper }}=E V_{k W h} \times \frac{90}{100}[k W h] \\
& S O C_{\text {Lower }}=E V_{k W h} \times \frac{80}{100}[k W h] \\
& S O C_{\text {Initial }}=E V_{k W h} \times \frac{85}{100}[k W h]
\end{aligned}
$$

Where,

$E V_{k W h}$ : the energy capacity of total EV

$C_{k W h}$ : the energy capacity of EV

$S O C_{U p p e r}$ : the upper limit of SOC

$S O C_{\text {Lower }}$ : the lower limit of SOC

$S O C_{\text {Initial }}:$ the initial SOC

The EV model is shown in Fig.9, and each prameter of EV shows in Table 3. We assume that EVs can charge and discharge with no time lags for input signal wthin the parameters of the energy capacity and power capacity. When the SOC reaches the upper limit or the lower limit, EV stops to charge or discharge.

Table 3. Parameter of EV

\begin{tabular}{|c|c|}
\hline Total battery capacity [p.u.MW] & $0.035(70 \mathrm{MW})$ \\
\hline Power capacity [kW] & 3 \\
\hline Energy capacity [kWh] & 24 \\
\hline Initial SOC [\%] & 85 \\
\hline Upper limit of SOC[\%] & 90 \\
\hline Lower limit of SOC[\%] & 80 \\
\hline
\end{tabular}

\subsection{Simulation condition}

Fig. 10 shows load disturbance of area- 1 and 2 . The size of the demand fluctuation in area- 1 and 2 is about $2 \%$ and $3 \%$ of each system capacity respectively. Fig. 11 shows the short term component (less than 20 minutes) of wind power fluctuation. The magnitude of wind power fluctuation is about $2 \%$ of the system capacity of area-2. It is assumed that 2.5 thousand units of EVs are penetrated in an assumption area, and $90 \%$ (2.3 thousand units) of them are defined the controllable EVs. To consider the EVs users' convenience, the SOC of EVs is operated between 80 to $90 \%$. We conduct simulations, one is the case without EV (pattern-1) and the other is the EVs introduction case (pattern-2).

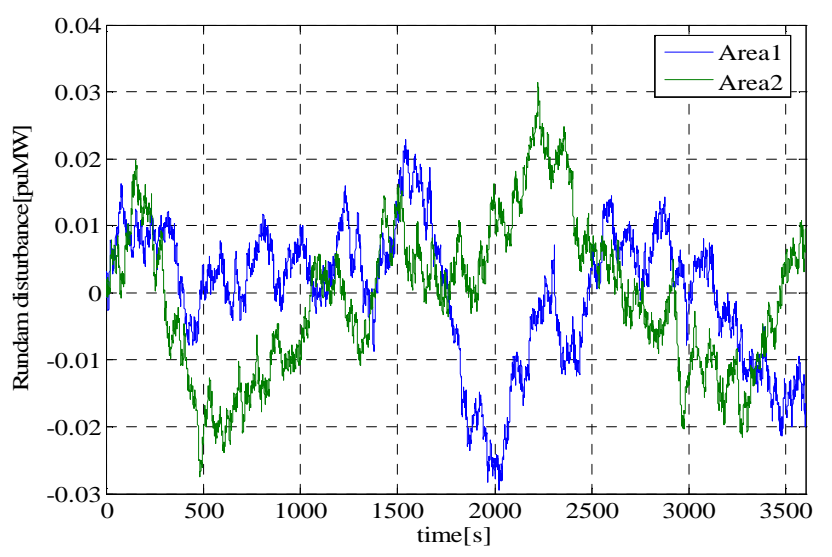

Fig. 10. Load disturbance 


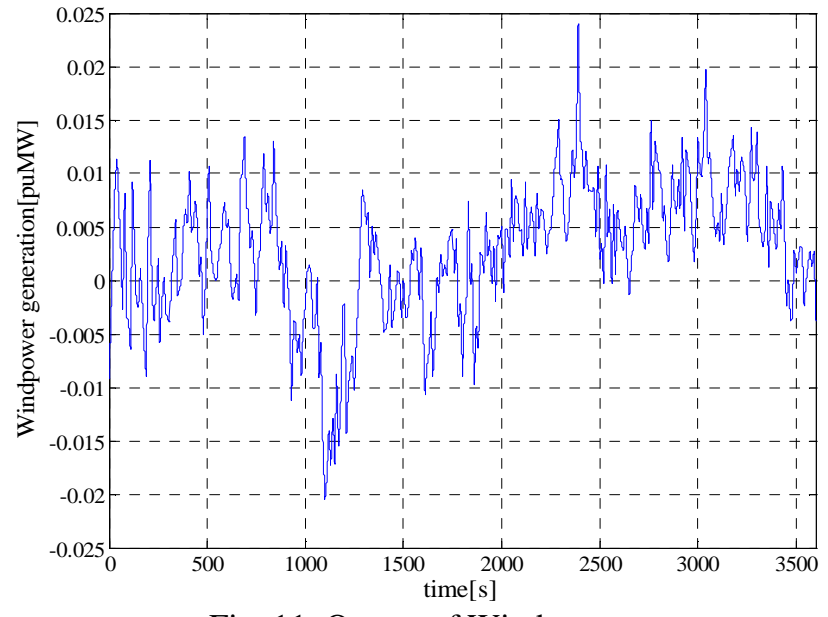

Fig. 11. Output of Wind power

\subsection{Application results}

\section{A. Frequency}

Fig. 12 and 13 show the frequency deviation of pattern-1 and pattern-2 in each area. Table 4 shows the standard deviation of frequency in each area. In pattern-1, the frequency deviation fluctuates and exceeds by $\pm 0.02 \mathrm{~Hz}$. On the contrary, the frequency deviation is decreasing within $\pm 0.0015 \mathrm{~Hz}$ in pattern-2. Also we compare the standard deviation of pattern- 1 and 2 , and pattern-2 is able to decrease the standard deviation by about $15 \%$ in area- 1 and $33 \%$ in area- 2 for pattern-1. The frequency variation in area- 2 that introduced EV is suppressed than area- 1 .

\section{B. Tie-line flow}

Fig.14 and 15 show the simulation result of tie-line flow deviation between area-1 and 2. Table 5 shows the standard deviation of the tie-line flow. Even if EVs are introduced in area-2, the tie-line flow deviation cannot be suppressed in tie line 1-2. Also, there is no change in the standard deviation of the tie-line flow. These results are due to the charge and discharge control of EVs managed only frequency deviation, and the control signal is not take into account both the frequency deviation and the tie-line flow deviation. Therefore, it is necessary to consider not only the frequency deviation but also the tie-line flow deviation and cooperation with the LFC generators and the EVs.

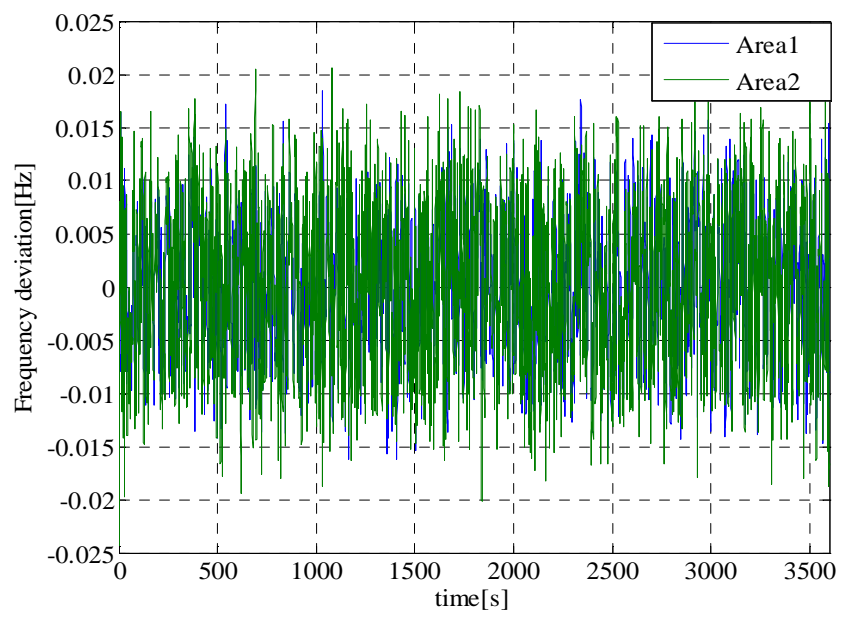

Fig. 12. Frequency deviation (pattern-1)

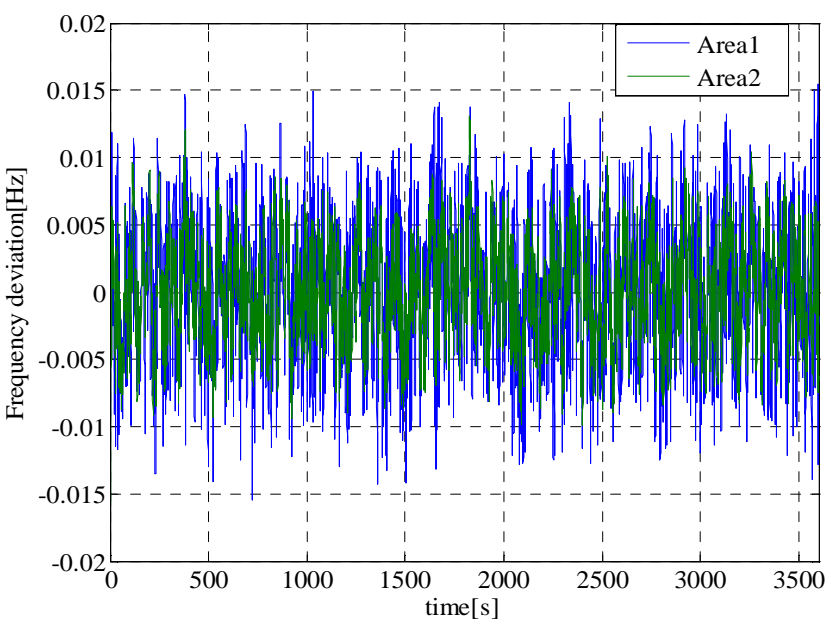

Fig. 13. Frequency deviation (pattern-2)

Table 4. Standard deviation of Frequency

\begin{tabular}{|c|c|c|}
\hline & Area-1 & Area-2 \\
\hline Pattern-1 & 0.005751 & 0.006437 \\
\hline Pattern-2 & 0.00488 & 0.004309 \\
\hline
\end{tabular}

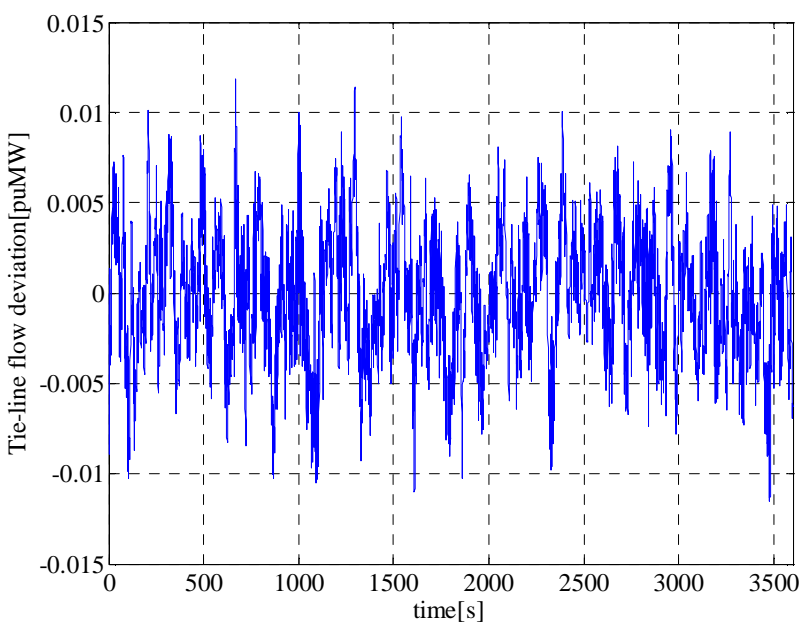

Fig. 14. Tie-line deviation (pattern-1)

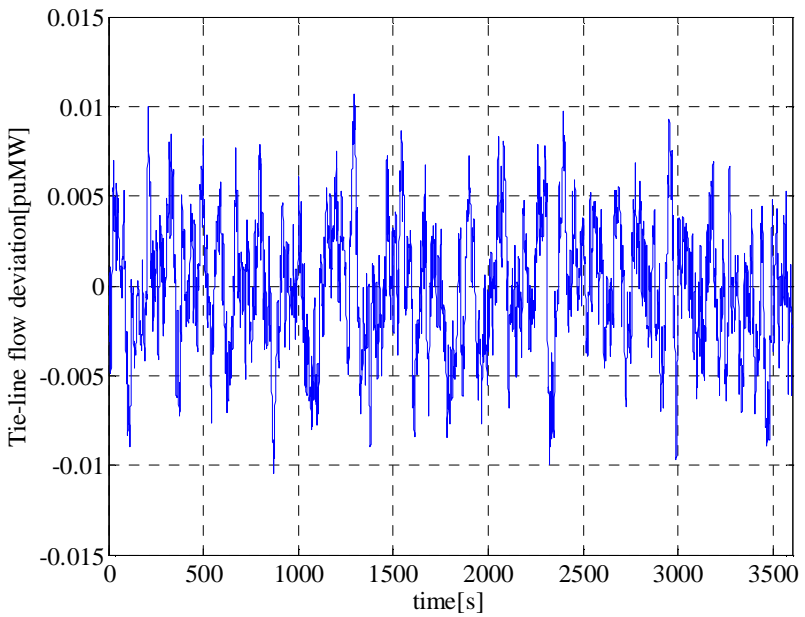

Fig. 15. Tie-line deviation (pattern-2)

Table 5. Standard deviation of Tie-line power flow

\begin{tabular}{|c|c|}
\hline & Areas 1-2 \\
\hline Pttern-1 & 0.003574 \\
\hline Pattern-2 & 0.003596 \\
\hline
\end{tabular}




\section{The EV output and the SOC}

Fig. 16 shows the output level of EVs. The positive output is discharge, and the negative output is charge of EVs. Fig. 17 shows the SOC of EVs. The SOC is able to maintain more than $80 \%$ which keeps convenience of the EVs' users.

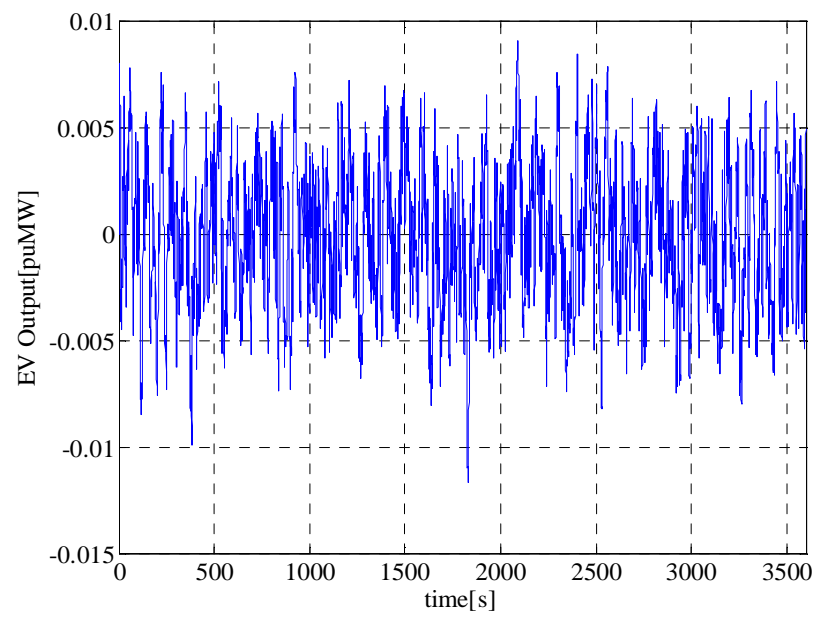

Fig. 16. Output of EV

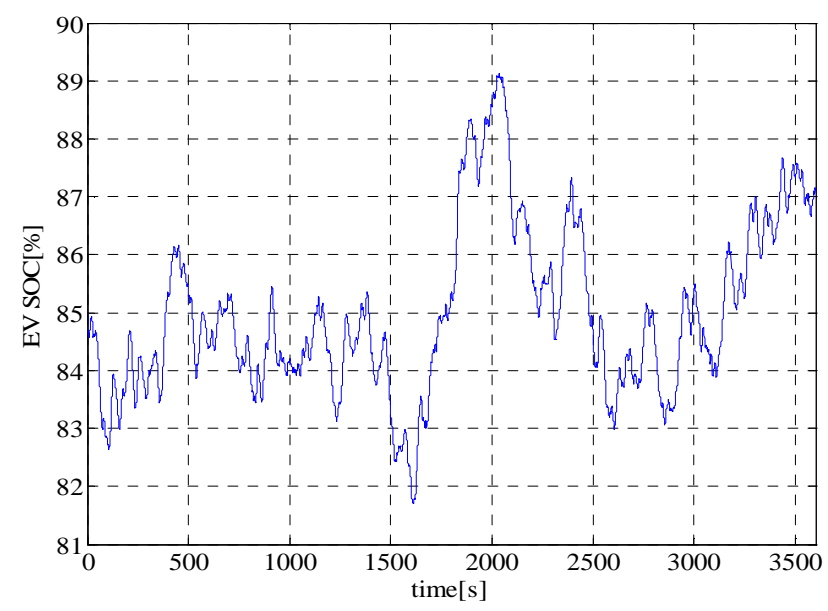

Fig. 17. State of Charge (SOC)

\section{Conclusion}

We revealed the smoothing effect of wind power fluctuations with comparing the power spectrum density of the integrated output of multiple wind generation sites (A, $\mathrm{B}$ and $\mathrm{C}$ sites) and a single site (A-1 site). The fluctuation of multiple sites is about one tenth smaller than that of the single site. If wind power generators are installed in a wide area, the smoothing effect can be expected compared with the case of a single generator installation. When we focus on the fluctuation related to the load dispatching control of power systems, the effectiveness of smoothing effect tends to increase in 20 minutes or less period fluctuations. Also, it is said that the influence on the frequency deviation by wind power fluctuations can be reduced due to the smoothing effect.

In the two-area interconnected power system introduced wind power generators and EVs, we examine a charging power control of batteries in EVs to suppress the frequency variation caused by wind power. As a result, the frequency deviation can be regulated, and the EV user's convenience is not spoiled by these charging controls of EVs.

\section{Reference}

[1] M. Asari, T. Nanahara, T. Maejima, K. Yamaguchi and T Sato, "A Study on Smoothing Effect on Output Fluctuation of Distributed Wind Power Generation", IEEE/PES2002, pp938-943

[2] T. Oozeki, K. Otani, T. Takahashi, Y. Hishikawa, G. Koshimizu and K. Ogimoto, "An evaluation method for smoothing effect on photovoltaic systems dispersed in a large area", Photovoltaic Specialists Conference (PVSC), 2009 34th IEEE, pp002250-002251

[3] N. Kawasaki, A. Usami, K. Nishioka, T. Shimakage, J. Sumita and H. Yamane, "Spatial interpolation of the solar irradiance; A study from the smoothing effect of irradiance fluctuatoins", Photovoltaic Specialists Conference (PVSC), 2011 37th IEEE, 001817-001821

[4] OLLE I.ELGERD and CHARLES E.FOSHA, JR, "Optimum Megawatt-Frequency Control of Multiarea Electric Energy Systems", IEEE Transaction on Power Apparatus and Systems, vol.PAS-89, No.4, 1970.

[5] CHARLES E.FOSHA,JR, OLLE I.ELGERD, "The Megawatt-Frequency Control Problem, "A New Approach Via Optimal Control Theory", IEEE Transaction on Power Apparatus and Systems, vol.PAS-89, NO.4, 1970.

[6] K. Shimizu, T. Masuta, Y. Ota and A. Yokoyama, "Load Frequency Control in Power System Using Vehicle-to-Grid System Considering the Customer Convenience of Electric Vehicles", Power System Technology (POWERCON), 2010 International Conference on, pp.1-8

[7] M. Takagi, K. Yamaji and H. Yamamoto, "Power System Stabilization by Charging Power Management of Plug-in Hybrid Electric Vehicles with LFC signal", Vehicle Power and Propulsion Conference, 2009. VPPC '09. IEEE, pp822826

[8] S. Shibasaki, M. Touge and S. Iwamoto, "Application of a NAS Battery System for improving Frequency Control", Power and Energy Society General Meeting, 2011 IEEE, pp1-6

[9] Jayakrishnan Radhakrishna Pillai, Birgitte Bak-Jensen, "Integration of Vehicle-to-Grid in the Western Danish Power System", IEEE Transactions on Sustainable Energy, VOL. 2, NO. 1, January 2011, pp12-19

[10] Y. Ota, H. Taniguchi, T. Nakajima, K. M. Liyanage, J. Baba, and A. Yokoyama, "Autonomous distributed V2G (vehicle-to-grid) considering charging request and battery condition," in Proc. IEEE PES Innov. Smart Grid Technol. Conf. Eur., Oct. 2010, pp. 1-6.

[11] Y. Ota, H. Taniguchi, T. Nakajima, K. M. Liyanage, J. Baba and A. Yokoyama, "Autonomous Distributed V2G (Vehicle-to-grid) Satisfying Scheduled Charging", IEEE Transactions on Smart Grid, VOL. 3, NO. 1, March 2012, pp559-564

[12] M. Datta, H. Ishikawa, H. Naitoh and T. Senjyu, "LFC by Coordinated Virtual Inertia Mimicking and PEVs in Power Utility with MW-class Distributed PV Generation", Control and Modeling for Power Electronics (COMPEL), 2012 IEEE 13th Workshop on, pp1-8 